\title{
PRODUTIVIDADE DA ÁGUA DE CHUVA EM CULTURAS DE SUBSISTÊNCIA NO SEMIÁRIDO PERNAMBUCANO
}

\section{LUIZA T. DE L. BRITO ${ }^{1}$, NILTON DE B. CAVALCANTI ${ }^{2}$, ADERALDO DE S. SILVA ${ }^{3}$, LÚCIO A. PEREIRA ${ }^{4}$}

RESUMO: Os diferentes sistemas de cultivo utilizados pelos agricultores do Semiárido brasileiro apresentam riscos de perdas devido às irregularidades das chuvas, sendo, portanto, necessário associá-los a práticas que propiciem maior disponibilidade de água no solo durante o ciclo de cultivo. Neste trabalho, objetivou-se avaliar a aplicação de quantidades mínimas de água e adubação orgânica na produtividade de feijãocaupi, cultivar BRS-Pujante e de milho, cultivar BRSCaatingueiro. Os resultados indicam que as maiores produtividades de grãos foram obtidas com o tratamento que associou a irrigação de salvação com a adubação orgânica, sendo para o feijão-caupi de $1.422,5 \mathrm{~kg} \mathrm{ha}^{-1}$, e para o milho, de $6.099,1 \mathrm{~kg} \mathrm{ha}^{-1}$, seguido pelo tratamento que usou somente a adubação orgânica, para ambas as culturas. Porém, comparando-se o efeito da adubação orgânica aplicada de forma isolada sobre a testemunha, observa-se que ocorreram aumentos de 54,5\% e de $237,3 \%$ nas produtividades de feijão e de milho, respectivamente, ressaltando a importância do uso da adubação orgânica nas culturas.

PALAVRAS-CHAVE: Vigna unguiculata, Zea mays L., irrigação de salvação, adubação.

\section{RAIN WATER PRODUCTIVITY IN SUBSISTENCE CROPS IN THE SEMIARID OF PERNAMBUCO}

\begin{abstract}
The different crop systems used by farmers in the Brazilian semiarid show risk of loss due to the rainfall irregularity being therefore necessary to associate them to practices that provide higher availability of soil water during the cropping season. This study aimed to evaluate the application of minimal amounts of water and organic fertilization on yields of cowpea, BRSPunjante cultivar (Vigna unguiculata (L.) Walp.) and maize, BRS-Caatingueiro cultivar (Zea mays L.). The results indicate that the highest yield of grain were obtained with the treatment which involved the salvation irrigation with organic manure, the cowpea $1,422.5 \mathrm{~kg} \mathrm{ha}^{-1}$ and the corn $6,099.1 \mathrm{~kg} \mathrm{ha}^{-1}$, followed by treatments that used only organic fertilization for both species. However, comparing the effect of organic manure applied alone on the control experiment were observed increases of $54.5 \%$ and $237,3 \%$ in yield of beans and maize, respectively, emphasizing the importance of the use of organic manure on crops.
\end{abstract}

KEWWORDS: Vigna unguiculata, Zea mays L., salvation irrigation, organic fertilization.

\footnotetext{
${ }^{1}$ Eng ${ }^{a}$ Agrícola, Dra., Pesquisadora, Embrapa Semiárido, Petrolina - PE, luizatlb@cpatsa.embrapa.br.

${ }^{2}$ Administrador de Empresas, M.Sc. em Extensão Rural, Embrapa Semiárido, Petrolina - PE, nbrito@cpatsa.embrapa.br.

${ }^{3}$ Eng ${ }^{0}$ Agrônomo, Ph.D., Pesquisador em Impacto Ambiental, Embrapa Semiárido, Petrolina - PE. aderaldo@cpatsa.embrapa.br, aderaldo@uol.com.br.

${ }^{4}$ Ecólogo, Dr. em Geociências e Meio Ambiente, Embrapa Semiárido, Petrolina - PE, lucio.ap@cpatsa.embrapa.br.

Recebido pelo Conselho Editorial em: 6-10-2010

Aprovado pelo Conselho Editorial em: 13-9-2011
} 


\section{INTRODUÇÃO}

No Semiárido brasileiro, a água é fator limitante tanto para o consumo das famílias e dos animais como para produção de alimentos. Nesta região, os sistemas de exploração agropecuários utilizados pelos pequenos agricultores sobrevivem em equilíbrio precário com os sistemas agroecológicos e socioeconômicos. O fenômeno que caracteriza esse desequilíbrio está associado, principalmente, à irregularidade pluviométrica, o que torna a agricultura uma atividade de risco.

Produzir alimentos nestas condições exige medidas de gestão e práticas apropriadas de uso e manejo da água e dos solos. Devido à agricultura irrigada consumir atualmente a maior parte da água doce disponível dos países em desenvolvimento, estimada entre 60 e $80 \%$ (CHISTOFIDIS, 2008), encontrar meios de produzir mais alimentos com menos água é um dos maiores desafios enfrentados pela humanidade. Assim, deve-se colocar em prática o conceito de "produtividade de água" apresentado por vários estudiosos, entre os quais, BLUEMLING et al. (2007). No contexto da agricultura, o aumento da produtividade de água está relacionado a vários fatores, como qualidade do material genético, práticas eficientes de manejo de água, práticas agronômicas e políticas de incentivo à produção. Entendido dessa forma, o aumento da produtividade da água pode ser uma resposta ao problema da escassez hídrica, principalmente considerando a água para produzir alimentos.

Neste espaço Semiárido, o potencial de águas subterrâneas pouco pode contribuir para reduzir os riscos da atividade agropecuária, pois, em geral, as águas apresentam baixas vazões e elevados teores de sais solúveis (LIMA et al., 1999). Nesse sentido, LACERDA et al. (2009) avaliaram os efeitos do uso de água salina em diferentes estádios de desenvolvimento de plantas de feijão-de-corda sobre a eficiência de utilização de água e de nutrientes. Nestes estudos, observaram que a irrigação com água salina nas fases da germinação e inicial de crescimento da cultura reduziu a eficiência de utilização da maioria dos nutrientes, considerando-se a produtividade de grãos. Por outro lado, a aplicação de água salina de forma contínua reduziu a eficiência agronômica de utilização de nutrientes, mas não afetou a eficiência de utilização dos nutrientes extraídos pelas plantas. Também, a aplicação de água salina nas fases de intenso crescimento e de reprodução da cultura permitiu maior economia de água de boa qualidade, sem causar impacto negativo na produtividade de grãos.

Analisar juntamente o efeito das práticas que conduzem a este atual conceito de eficiência de água com os da escassez de recursos hídricos no Semiárido brasileiro tem sido objeto de vários estudos realizados pela Embrapa Semiárido, resultando em diferentes alternativas tecnológicas voltadas para aumentar a disponibilidade de água para consumo humano, animal e produção de alimentos nas comunidades rurais, como as pequenas estruturas hídricas representadas pelas cisternas para consumo humano, animal e vegetal; barragem subterrânea; captação in situ e pequenas barragens para uso na irrigação de salvação (BRITO et al., 2007). Nestas condições edafoclimáticas, foram avaliadas as perdas de solo e de água sob diferentes métodos de captação de água de chuva in situ, em área cultivada com milho (Zea mays L.), sendo observado que o método Guimarães Duque proporcionou maiores perdas de água $(6.696 \mathrm{~L})$ e de solo $\left(15.225 \mathrm{~kg} \mathrm{ha}^{-1}\right)$, enquanto as menores perdas de água $(1.066 \mathrm{~L})$ e de solo $\left(1.022 \mathrm{~kg} \mathrm{ha}^{-1}\right)$ e a maior produtividade da cultura $\left(606 \mathrm{~kg} \mathrm{ha}^{-1}\right)$ foram obtidas com o método de sulcos barrados (BRITO et al., 2008), apresentando-se, assim, como o sistema mais indicado para as condições analisadas.

No Semiárido brasileiro, os primeiros estudos utilizando a prática da irrigação de salvação, no âmbito da agricultura de subsistência, foram referendados no modelo de uma pequena barragem de terra para armazenar água de chuva (Figura 1), aplicá-la às culturas nos veranicos que ocorrem na estação chuvosa, como forma de reduzir os riscos de perda de safra. Na irrigação de salvação, a aplicação de água deve ser efetuada quando a planta apresentar sintomas de deficiência de água, para que não afete o desenvolvimento das culturas e não comprometa sua produção, embora o ideal seja realizar o monitoramento da umidade do solo para definir o momento da irrigação (SILVA et al., 2007). 


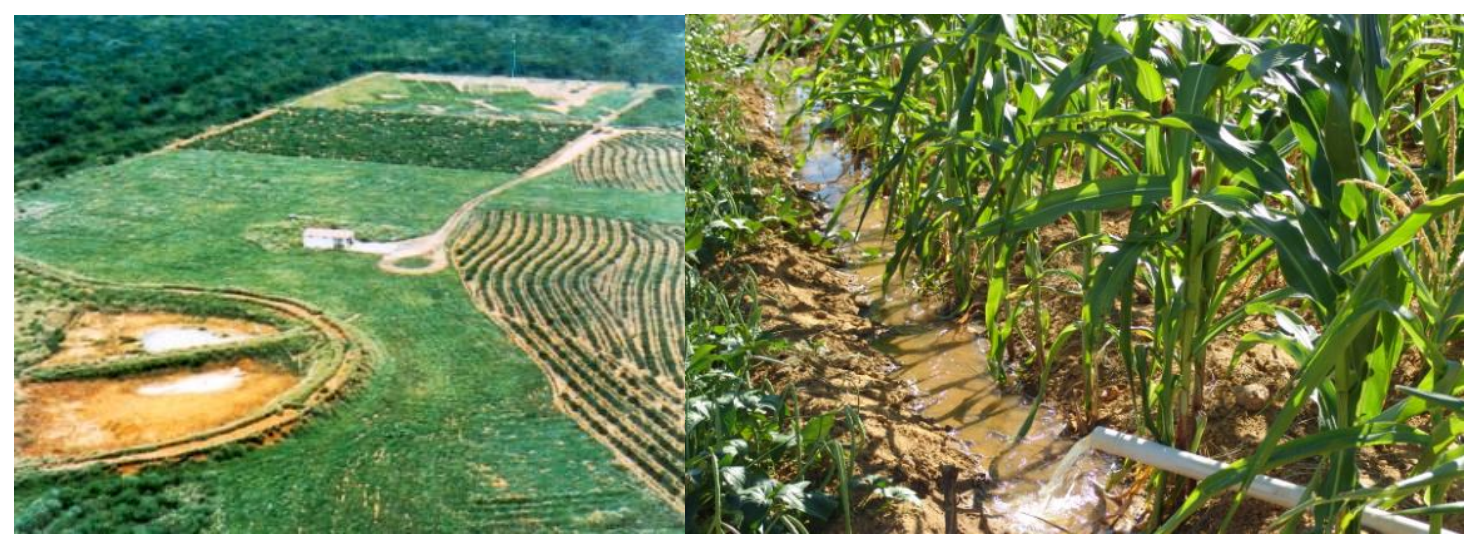

FIGURA 1. Barragem para armazenamento da água de chuva para uso na irrigação de salvação. Dam to store rainwater for use in the salvation irrigation.

Entre as culturas de subsistência do Nordeste brasileiro, o feijão-vigna (Vigna unguiculata (L.) Walp.), também conhecido como feijão-macassar ou feijão-de-corda, é uma das variedades mais consumidas. Da mesma forma, o milho (Zea mays L.) também é extensivamente utilizado como alimento humano, devido às suas qualidades nutricionais.

Nesse cenário, a utilização de variedades precoces, associada a técnicas que aumentam a disponibilidade de água no solo, poderão reduzir os riscos de exploração dessas culturas, proporcionando melhoria da produtividade dos sistemas de produção dos pequenos e médios produtores rurais do Semiárido brasileiro. Entre as cultivares de feijão-caupi e de milho com estas características, a BRS-Pujante e BRS-Caatingueiro, respectivamente, têm proporcionado redução nos períodos de colheitas e maiores produtividades médias, o que contribui para seu plantio em áreas semiáridas (CARVALHO et al., 2004). Neste estudo, foram avaliados os efeitos da irrigação de salvação e da adubação orgânica na produtividade de feijão-caupi e milho.

\section{MATERIAL E MÉTODOS}

Os estudos foram conduzidos no período de março a junho de 2008, na Estação Experimental da Embrapa Semiárido, onde o clima é classificado como Semiárido quente BSw'h, conforme classificação de Köeppen (latitude: $09^{\circ} 05^{\prime} \mathrm{S}$, longitude: $40^{\circ} 24^{\prime} \mathrm{W}$, altitude: $379 \mathrm{~m}$ ). Apresenta temperatura média anual de $26,3{ }^{\circ} \mathrm{C}$ e precipitação média anual é de $566,7 \mathrm{~mm}$ (MOURA et al., 2007). O solo da área experimental foi classificado como Argissolo Amarelo eutrófico abrúptico plíntico, que são solos medianamente profundos, moderadamente drenados, textura arenosa ou média, com baixos teores de matéria orgânica (SANTOS et al., 2006). Demais características físicas e químicas do solo estão apresentadas na Tabela 1.

TABELA 1. Características físicas e químicas do solo da área experimental. Physical and chemical characteristics of the experimental area.

\begin{tabular}{|c|c|c|c|c|c|c|c|}
\hline \multirow{2}{*}{$\begin{array}{l}\text { Prof. } \\
\text { (m) }\end{array}$} & \multicolumn{3}{|c|}{$\begin{array}{c}\text { Granulometria } \\
(\%)\end{array}$} & \multicolumn{2}{|c|}{$\begin{array}{l}\text { Densidade } \\
\left(\mathrm{kg} \mathrm{m}^{-3}\right)\end{array}$} & \multicolumn{2}{|c|}{$\begin{array}{l}\text { Água Retida } \\
\text { (atm) }\end{array}$} \\
\hline & Areia & Silte & Argila & Partícula & Solo & 0,33 & 15 \\
\hline $0-0,20$ & 81,03 & 9,54 & 9,44 & 2,58 & 1,49 & 8,06 & 4,35 \\
\hline $0,20-0,40$ & 73,69 & 8,75 & 17,56 & 2,56 & 1,42 & 12,37 & 7,57 \\
\hline \multicolumn{8}{|c|}{ Características Químicas } \\
\hline $\begin{array}{cc}\mathrm{pH} & \begin{array}{c}\mathrm{P}^{+} \\
\mathrm{mg} \mathrm{dm}^{3}\end{array} \\
\end{array}$ & $\mathrm{~K}^{+}$ & $\mathrm{Ca}^{++}$ & $\begin{array}{ll}\mathrm{Mg}^{++} & \mathrm{Al}^{++} \\
-{ }^{\mathrm{c}} \mathrm{mol}_{\mathrm{c}} \mathrm{dm}^{-3}\end{array}$ & $\mathrm{H}+\mathrm{Al}$ & $\mathrm{S}_{\text {(base) }} \mathrm{CTC}$ & $\begin{array}{c}\mathrm{CE} \\
\mathrm{dS \textrm {Sm } ^ { - 1 }}\end{array}$ & $\begin{array}{l}\text { M.O. } \\
\mathrm{g} \mathrm{kg}^{-1}\end{array}$ \\
\hline 4,0 & 0,23 & 2,1 & 0,5 & 0,11 & 4,75 & 0,20 & 7,45 \\
\hline
\end{tabular}


O preparo do solo foi realizado utilizando-se de aração, gradagem e sulcamento. O delineamento experimental foi o inteiramente casualizado, com quatro tratamentos, constituindo-se de: T1: irrigação de salvação e adubação orgânica; T2: irrigação de salvação; T3: adubação orgânica; T4: cultivo em condições de sequeiro sem adubação orgânica, considerada como testemunha, e três repetições. As parcelas experimentais foram formadas por quatro sulcos com 30,0 m de cumprimento, com as repetições com $10 \mathrm{~m}$ cada, tanto para o caupi quanto para o milho. A adubação orgânica consistiu-se da aplicação de $24 \mathrm{~kg}$ de esterco bovino por metro linear de sulco, nos tratamentos T1 e T3, com o objetivo de melhorar as características do solo, principalmente macronutrientes (NPK).

Para se efetuar a aplicação de água nas culturas do feijão-caupi e do milho, por meio das irrigações de salvação, foram considerados os estádios de desenvolvimento dessas culturas, o período de ocorrência de chuvas e o volume total precipitado na área do experimento. Neste sentido, sempre que ocorreram veranicos, ou seja, ausência de chuvas por mais de uma semana no período de cultivo, foram aplicados 24 litros de água por metro quadrado, que corresponde a uma lâmina média de $24 \mathrm{~mm}$, distando da planta 0,20-0,30 m, aproximadamente.

As cultivares de caupi BRS-Pujante e milho BRS-Caatingueiro foram semeadas, colocando-se cinco sementes por cova, de acordo com cada parcela experimental, no espaçamento de 1,0 $\mathrm{m} \mathrm{x}$ 0,4 m. Após a germinação, foi realizado o desbaste, deixando-se apenas duas plantas por cova.

O plantio das sementes do feijão-caupi e do milho foi efetuado em 03 de março de 2008, após a ocorrência de $79,1 \mathrm{~mm}$ de chuva, entre os dias 27 de fevereiro e $1^{\mathrm{o}}$ de março, proporcionando umidade ao solo favorável à germinação das sementes, que ocorreu cinco dias após o semeio. Foram avaliados produtividade, altura da planta, diâmetro basal, número de vagens ou número de espigas por planta e fitomassa verde e seca.

O peso da matéria seca foi obtido a partir de uma amostra ao acaso, de 25 plantas por tratamento. As plantas foram secas em estufa à temperatura média de $60-70^{\circ} \mathrm{C}$, até atingir peso constante. Para a avaliação da produtividade de grãos, após a secagem, as vagens e as espigas foram debulhadas, e os grãos pesados, de acordo com cada tratamento, e transformados em $\mathrm{kg} \mathrm{ha}^{-1}$ (13\% base úmida). A análise de variância e as médias foram comparadas por meio do teste de Tukey, a $5 \%$ de probabilidade.

\section{RESULTADOS E DISCUSSÃO}

No período de 15 de março a 16 de abril, que compreendeu as primeiras fases de desenvolvimento dessas culturas, ocorreram $199 \mathrm{~mm}$ de chuva, de forma bem distribuída no tempo, (Figura 2), de modo que, no final do ciclo produtivo, foram aplicadas cinco e oito irrigações de salvação no feijão-caupi e no milho, respectivamente, numa frequência semanal.

Pode-se observar na Figura 2 que, no período de 3 de março (plantio) a 28 de abril, ocorreram $200,1 \mathrm{~mm}$ de precipitações pluviométricas, dos quais, $82,0 \mathrm{~mm}$ em apenas um dia ( $\left.{ }^{\circ}-04\right)$, o que favoreceu o desenvolvimento do feijão-caupi e do milho cultivados nas fases iniciais. Porém, as baixas precipitações pluviométricas ocorridas a partir de 3 de abril, num total de apenas 22,2 mm, implicaram a necessidade de água para as culturas nas fases de enchimento de grãos e maturação. Dessa forma, foram aplicados $120 \mathrm{~mm}$ e $192 \mathrm{~mm}$ de água nas culturas do feijão-caupi e do milho, respectivamente, a partir de 28 de abril, numa frequência semanal, tendo em vista que, no tratamento sem a aplicação de água, as culturas apresentaram sintomas de murchamento, principalmente a cultura do milho, com reflexos na redução das produtividades. 


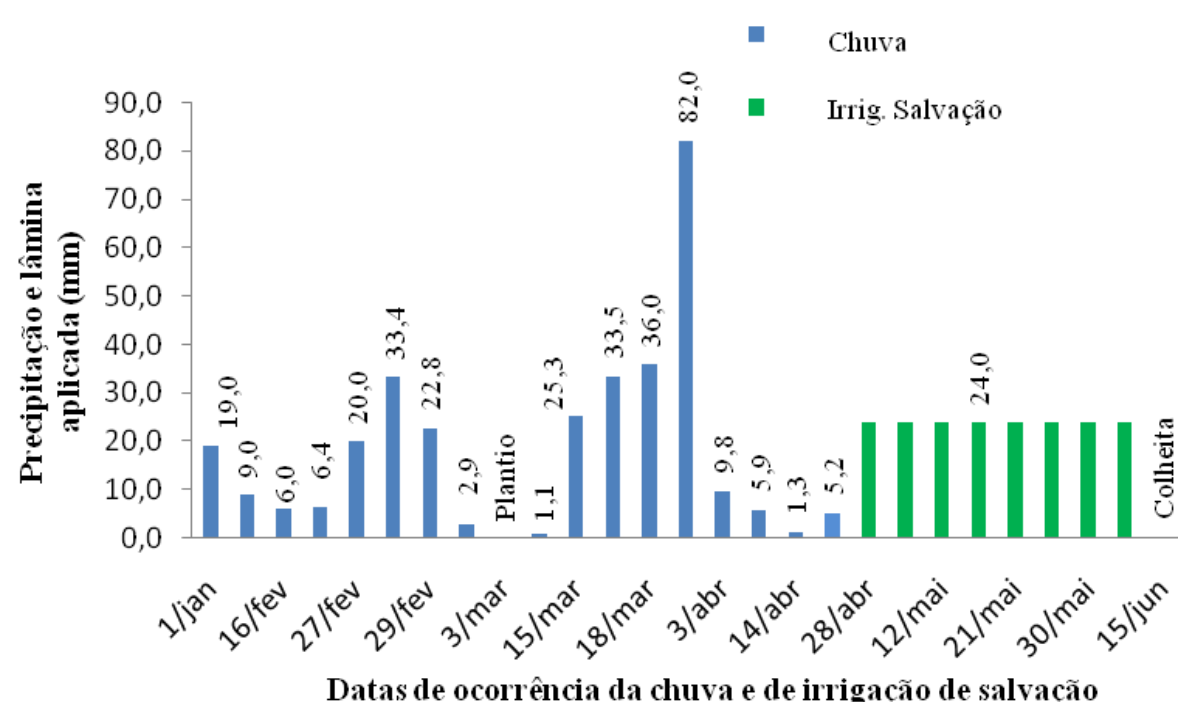

FIGURA 2. Ocorrência das chuvas e água aplicada no período de desenvolvimento das culturas do caupi e do milho. Rainfall occurrence and water applied during the crop growth of cowpea and maize.

LIMA (1989), citado por ANDRADE JUNIOR et al. (2003), ressalta que as necessidades de água do feijão-caupi podem variar de 300 a $450 \mathrm{~mm} / \mathrm{ciclo}$, dependendo da cultivar, do solo e das condições climáticas locais. O consumo hídrico diário raramente excede $3,0 \mathrm{~mm}$, quando a planta está na fase inicial de desenvolvimento. Para as condições edafoclimáticas de Teresina-PI, encontraram-se valores da ordem de $2,1 \mathrm{~mm} \mathrm{dia}^{-1}$ para a variedade BR 10-Piauí. Considerando o total das chuvas e as irrigações de salvação ocorridas, a lâmina de água total aplicada no ciclo do feijão-caupi foi de 398,1, valor este entre os limites apresentados por LIMA (1989).

Pode-se observar que não ocorreu diferença estatística para altura de plantas de caupi entre T1, T2 e T3. Na avaliação da produtividade do feijão-caupi entre os tratamentos avaliados, observou-se que não houve diferença entre os tratamentos T1 e T3, sendo a produtividade obtida com T1 igual a 1.422,5 kg ha- ${ }^{1}$ de grãos, seguido por T3 (1.385,8 kg ha ${ }^{-1}$ ) (Tabela 2). Nos demais tratamentos, foram evidenciados os efeitos da irrigação de salvação e da adubação orgânica em relação à testemunha (T4). Analisando-se o efeito dos tratamentos isolados em relação à testemunha, observa-se que os maiores incrementos foram de 54,5\% entre T1:T4 e de 50,5\% entre T2:T4, evidenciando-se, assim, a contribuição da maior oferta de água para as plantas, proporcionada pela irrigação de salvação, pela adubação orgânica, como também pela regularidade na distribuição das chuvas durante o ciclo de desenvolvimento da cultura. Para os demais parâmetros avaliados, os resultados encontram-se na Tabela 2.

TABELA 2. Altura de planta (m), diâmetro basal (m), número de vagem, matéria seca e verde $(\mathrm{kg})$ e produtividade do caupi $\left(\mathrm{kg} \mathrm{ha}^{-1}\right)$ obtidos com os diferentes tratamentos. Plant height $(\mathrm{m})$, basal diameter $(\mathrm{m})$, number of pods, dry and green matter (kg) and yield of cowpea $\left(\mathrm{kg} \mathrm{ha}^{-1}\right)$ obtained from different treatments.

\begin{tabular}{ccccccc}
\hline Tratamentos & $\begin{array}{c}\text { Altura da } \\
\text { planta }(\mathrm{m})\end{array}$ & $\begin{array}{c}\text { Diâmetro } \\
\text { basal }(\mathrm{m})\end{array}$ & $\begin{array}{c}\mathrm{N}^{\mathrm{o}} \text {. de } \\
\text { vagens }\end{array}$ & $\begin{array}{c}\text { Matéria } \\
\text { verde }(\mathrm{kg})\end{array}$ & $\begin{array}{c}\text { Matéria seca } \\
(\mathrm{kg})\end{array}$ & $\begin{array}{c}\text { Produtividade } \\
\text { grãos }\left(\mathrm{kg} \mathrm{ha}^{-1}\right)\end{array}$ \\
\hline $\mathrm{T} 1$ & $0,37 \mathrm{a}$ & $0,57 \mathrm{a}$ & $8,1 \mathrm{a}$ & $0,086 \mathrm{a}$ & $0,019 \mathrm{a}$ & $1.422,5 \mathrm{a}$ \\
$\mathrm{T} 2$ & $0,37 \mathrm{a}$ & $0,44 \mathrm{~b}$ & $6,1 \mathrm{~b}$ & $0,053 \mathrm{~b}$ & $0,014 \mathrm{~b}$ & $1.050,0 \mathrm{~b}$ \\
$\mathrm{~T} 3$ & $0,36 \mathrm{a}$ & $0,35 \mathrm{c}$ & $5,94 \mathrm{~b}$ & $0,047 \mathrm{c}$ & $0,010 \mathrm{c}$ & $1.385,8 \mathrm{a}$ \\
$\mathrm{T} 4$ & $0,31 \mathrm{~b}$ & $0,26 \mathrm{~d}$ & $3,83 \mathrm{c}$ & $0,038 \mathrm{~d}$ & $0,009 \mathrm{c}$ & $920,8 \mathrm{c}$ \\
\hline Média & 0,35 & 0,41 & 5,95 & 0,062 & 0,014 & $1.171,6$ \\
\hline
\end{tabular}


No Semiárido brasileiro, tradicionalmente o caupi é cultivado em regime de sequeiro, porém, nestas condições, a produtividade média alcançada no âmbito dos produtores é da ordem de $300 \mathrm{~kg} \mathrm{ha}^{-1}$ de grãos e, em condições irrigadas, pode atingir $1.520 \mathrm{~kg} \mathrm{ha}^{-1}$ de grãos (SANTOS et al., 2002). Cita-se também que as variedades mais cultivadas em áreas irrigadas são IPA 206, EPACE 10 e Canapu Precoce. Estes autores avaliaram diferentes cultivares e genótipos de feijãocaupi com o objetivo de estudar sua adaptabilidade e estabilidade de rendimento em regime irrigado e de sequeiro, em diferentes tipos de solos e sem adubação, e obtiveram produtividades de 1.623 e $1.107 \mathrm{~kg} \mathrm{ha}^{-1}$ de grãos, respectivamente, em áreas irrigadas e de sequeiro; produtividades estas compatíveis com as obtidas nestes estudos.

Com a cultura do milho, os resultados obtidos (Tabela 3) indicam semelhança entre os tratamentos T1 (irrigação de salvação + adubação orgânica) e T3 (adubação orgânica) para altura de planta. Porém, na avaliação da produtividade de grãos, todos os tratamentos apresentaram diferença estatística, evidenciando-se o efeito conjunto da irrigação de salvação e da adubação orgânica, sendo a produtividade de T1 igual a $6.099,1 \mathrm{~kg} \mathrm{ha}^{-1}$ de grãos, seguido por T3 com $4.805,0 \mathrm{~kg} \mathrm{ha}^{-1}$ de grãos. Observando-se os efeitos da irrigação de salvação (T2) e da adubação orgânica (T3) de forma isolada, sobre a testemunha (T4), nota-se, que com T2, ocorreu mais que o dobro da produtividade de grãos e quase o triplo com T3, respectivamente. Para os demais parâmetros, os resultados apresentaram diferença estatística em todos os tratamentos, comportamento semelhante ao da cultura do feijão-caupi.

TABELA 3. Altura de planta (m), diâmetro basal (m), número de espigas, peso da espiga (kg), matéria seca e verde $(\mathrm{kg})$ e produtividade do milho obtidos com os diferentes tratamentos. Plant height (m), basal diameter (m), cob number, cob weight (kg), dry and green matter $(\mathrm{kg})$ and corn yields obtained with different treatments.

\begin{tabular}{cccccccc}
\hline \multirow{2}{*}{ Tratamentos } & $\begin{array}{c}\text { Altura da } \\
\text { Planta }(\mathrm{m})\end{array}$ & $\begin{array}{c}\text { Diâmetro } \\
\text { Basal }(\mathrm{m})\end{array}$ & $\begin{array}{c}\mathrm{N}^{\mathrm{o}} . \mathrm{de} \\
\text { Espiga }\end{array}$ & $\begin{array}{c}\text { Peso de } \\
\text { Espiga }(\mathrm{kg})\end{array}$ & $\begin{array}{c}\text { Matéria } \\
\text { Verde }(\mathrm{kg})\end{array}$ & $\begin{array}{c}\text { Matéria } \\
\text { Seca }(\mathrm{kg})\end{array}$ & $\begin{array}{c}\text { Produtividade } \\
\text { Grãos }\left(\mathrm{kg} \mathrm{ha}^{-1}\right)\end{array}$ \\
\hline $\mathrm{T} 1$ & $1,75 \mathrm{a}$ & $0,18 \mathrm{a}$ & $1,2 \mathrm{a}$ & $0,28 \mathrm{a}$ & $0,43 \mathrm{a}$ & $0,51 \mathrm{a}$ & $6.099,10 \mathrm{a}$ \\
$\mathrm{T} 2$ & $1,52 \mathrm{~b}$ & $0,11 \mathrm{c}$ & $0,67 \mathrm{c}$ & $0,18 \mathrm{c}$ & $0,14 \mathrm{c}$ & $0,08 \mathrm{c}$ & $3.982,5 \mathrm{c}$ \\
$\mathrm{T} 3$ & $1,69 \mathrm{a}$ & $0,15 \mathrm{~b}$ & $0,88 \mathrm{~b}$ & $0,25 \mathrm{~b}$ & $0,34 \mathrm{~b}$ & $0,13 \mathrm{~b}$ & $4.805,0 \mathrm{~b}$ \\
$\mathrm{~T} 4$ & $1,21 \mathrm{c}$ & $0,07 \mathrm{~d}$ & $0,60 \mathrm{~d}$ & $0,17 \mathrm{c}$ & $0,14 \mathrm{c}$ & $0,06 \mathrm{~d}$ & $1.808,3 \mathrm{~d}$ \\
\hline Média & 1,54 & 0,12 & 0,90 & 0,22 & 0,28 & 0,10 & $3.953,3$ \\
\hline
\end{tabular}

A cultivar de milho BRS-Caatingueiro apresenta potencial genético para atingir produtividades de até $5.000 \mathrm{~kg} \mathrm{ha}^{-1}$, com valores médios entre 2.000 e $3.000 \mathrm{~kg} \mathrm{ha}^{-1}$ para as condições semiáridas (CARVALHO et al., 2004).

Os valores de produtividade do milho BRS-Caatingueiro obtidos nesta pesquisa assemelham-se aos valores obtidos por WENDLING et al. (2002) e SUZUKI \& ALVES (2004), em que obtiveram $5.893 \mathrm{~kg} \mathrm{ha}^{-1}$, com um total de $816,8 \mathrm{~mm}$ de chuva no ciclo de cultivo, e com $5.258 \mathrm{~kg} \mathrm{ha}^{-1}$, com precipitações superiores a $1.000 \mathrm{~mm}$, respectivamente. Considerando o total das chuvas e as irrigações de salvação ocorridas, a lâmina de água total aplicada no ciclo do milho correspondeu a $470,1 \mathrm{~mm}$.

DOORENBOS \& KASSAN (1979) ressaltam que a quantidade de água necessária durante seu ciclo produtivo é, em média, de 500,0-800,0 $\mathrm{mm}$. Afirmam, ainda, que o rendimento máximo de uma cultura é aquele obtido com uma variedade altamente produtiva e bem adaptada ao respectivo ambiente de crescimento, cultivada em condições em que não haja limitação de fatores como água e nutrientes, e controle de pragas e doenças, durante seu cultivo até o amadurecimento; em geral, a diminuição na produtividade, ocasionada por déficit hídrico durante o período vegetativo e de maturação, é relativamente pequena, enquanto durante o florescimento e os períodos de formação da produtividade será maior. 
Segundo dados do FIBGE (2006), em 2005, as produções médias de milho cultivado em condições dependentes de chuva nos Estados do Piauí, Ceará, Rio Grande do Norte, Paraíba, Pernambuco e Alagoas, foram de 661; 497; 465; 402; 560 e $475 \mathrm{~kg} \mathrm{ha}^{-1}$, respectivamente.

Os resultados de produtividade obtidos tanto para o caupi quanto para o milho ressaltam a importância do uso destas práticas em condições de cultivos dependentes de chuva, como ressaltado no conceito de "produtividade da água", embora sejam pouco utilizadas pelos agricultores, que preferem vender o esterco do curral, muitas vezes, a baixos custos.

\section{CONCLUSÕES}

- O efeito conjunto da irrigação de salvação e da adubação orgânica proporcionou aumentos de $54,5 \%$ e de $237,3 \%$ nas produtividades do feijão-caupi e do milho quando comparados aos valores obtidos em condições dependentes de chuva (testemunha).

- As produtividades obtidas devem-se, provavelmente, aos efeitos da adubação orgânica e da irrigação de salvação, onde foram potencializadas as características genéticas destas cultivares.

- Os sistemas de produção agrícola dependentes de chuva do Semiárido brasileiro necessitam estar associados a práticas que aumentem a umidade no perfil do solo e reduzam os efeitos da irregularidade climática.

\section{REFERÊNCIAS}

ANDRADE JÚNIOR, A. S. de; SANTOS, A.A. dos; ATHAYDE SOBRINHO, C.; BASTOS. E.A.; MELO, F. de B.; VIANA, F.M.; FREIRE FILHO, F.R.; CARNEIRO, J. da S.; ROCHA, M. de M.; CARDOSO, M.J.; SILVA, P.H.S. da; RIBEIRO, V.Q. Cultivo de feijão-caupi. Teresina: Embrapa Meio-Norte, 2003. (Sistemas de Produção, 2). Disponível em:

<http://sistemasdeproducao.cnptia.embrapa.br/FontesHTML/Feijao/FeijaoCaupi/index.htm>. Acesso em: 22 abr. 2009.

BLUEMLING, B.; YANG, H.; PAHL-WOSTL, C. Making water productivity operational - A concept of agricultural water productivity exemplified at a wheat-maize cropping pattern in the North China plain, Agricultural Water Management, v.91, n.1-3, p.11-23, 2007.

BRITO, L.T.L; CAVALCANTI, N.B.; ANJOS, J.B. dos; SILVA, A. de S.; PEREIRA, L.A. Perdas de solo e de água em diferentes sistemas de captação in situ no Semiárido brasileiro. Engenharia Agrícola, Jaboticabal, v.28, n.3, p.507-515, 2008.

BRITO, L.T. de L.; MOURA, M.S.B. de; GAMA, G.F.B. (Ed.). Potencialidades da água de chuva no Semiárido brasileiro. Petrolina: Embrapa Semiárido, 2007. 181 p.

CARVALHO, H.W.L. de; SANTOS, M.X. dos; SILVA, A.A.G. da; CARDOSO, M.J.; SANTOS, D.M. dos; TABOSA, J.N.; MICHEREFF FILHO, M.; LIRA, M.A.; BOMFIM, M.H.C.; SOUZA, E.M. de; SAMPAIO, G.V.; BRITO, A.R. de M.B.; DOURADO, V.V.; TAVARES, J.A.; NASCIMENTO NETO, J.G. do; NASCIMENTO, M.M.A. do; TAVARES FILHO, J.J.; ANDRADE JÚNIOR, A.S. de; CARVALHO, B.C.L. de. Caatingueiro - uma variedade de milho para o Semiárido nordestino. Aracaju: Embrapa Tabuleiros Costeiros, 2004. 8 p. (Comunicado Técnico, 29).

CHRISTOFIDIS, D. Água, irrigação e segurança alimentar. Revista Item, Brasília, n.77, p.16-21, 2008.

DOORENBOS, J.E.; KASSAM, A.H. Yield response to water. Roma: FAO, 1979. 193p. (FAO, Irrigation and Drainage Paper, 33).

FIBGE - FUNDAÇÃO INSTITUTO BRASILEIRO DE GEOGRAFIA E ESTATÍSTICA.

Produção agrícola municipal 2005. Disponível em: <http://www.ibge.gov.br>. Acesso em: 5 set. 2006. 
LACERDA, C.F. de; NEVES, A.L.R.; GUIMARÃES, F.V.A.; SILVA, F.L.B. da; PRISCO, J.T.; GHEYI, H.R. Eficiência de utilização de água e nutrientes em plantas de feijão-de-corda irrigadas com água salina em diferentes estádios de desenvolvimento. Engenharia Agrícola, Jaboticabal, v.29, n.2, p.221-230, 2009.

LIMA, M.G. Evapotranspiração da cultura do feijão macássar (Vigna unguiculata L. Walp.). In : CONGRESSO BRASILEIRO DE AGROMETEOROLOGIA, 6., 1989, Maceió. Anais . . . Maceió: SBA, 1989. p.275-282.

LIMA, J.E.F.W.; FERREIRA, R.S.A.; CHRISTOFIDIS, D. O uso da irrigação no Brasil. In: FREITAS, M.A.V. de. (Ed.). O estado das águas no Brasil: perspectivas de gestão e informações de recursos hídricos. Brasília: ANEEL-SRH/MME/MMA-SRH/OMM, 1999. p. 73-82.

MOURA, M.S.B. de; GALVINCIO, J.D.; BRITO, L.T. de L.; SILVA, A. de S.; SÁ, I.I. de; LEITE, W. de M. Influência da precipitação pluviométrica nas áreas de captação de água de chuva na Bahia. In: SIMPÓSIO BRASILEIRO DE CAPTAÇÃO E MANEJO DE ÁGUA DE CHUVA, 6., 2007, Belo Horizonte. Anais... Belo Horizonte: UFMG, 2007. 1 CD-ROM.

SANTOS, C.A.F.; ARAUJO, F.P.; MENEZES, E.A. Comportamento produtivo de caupi em regimes irrigado e de sequeiro em Petrolina e Juazeiro. Pesquisa Agropecuária Brasileira, Brasília, v.35, n.11, p.2.229-2.234, 2002.

SANTOS, H.G. dos; JACOMINE, P.K.T.; ANJOS, L.H.C. dos; OLIVEIRA, V.A. de; OLIVEIRA, J.B. de; COELHO, M.R.; LUMBRERAS, J.F.; CUNHA, T.J.F. (Ed.). Sistema brasileiro de classificação de solos. 2.ed. Rio de Janeiro: Embrapa Solos, 2006. 306 p.

SILVA, A. de S.; MOURA, M.S.B. de; BRITO, L.T. de L. Irrigação de salvação em culturas de subsistência. In: BRITO, L.T. de L.; MOURA, M.S.B. de; GAMA, G.F.B. (Ed.). Potencialidades da água de chuva no Semiárido brasileiro. Petrolina: Embrapa Semiárido, 2007. cap. 8, p.159-179.

SUZUKI, L.E.A.S.; ALVES, M.C. Produtividade do milho (Zea mays L.) influenciada pelo preparo do solo e por plantas de cobertura em Latossolo Vermelho. Acta Scientiarum Agronomy, Maringá, v.26, n.1, p.61-65, 2004.

WENDLING, A.; ELTZ, F.L.F.; DIDONÉ, A. JR.; COGO, C.M.; SANTOS, M.V.C.; BECKER, M.W. Produtividade de grãos e massa seca de milho sob plantio direto no período de 1998-2002. In: REUNIÃO BRASILEIRA DE MANEJO E CONSERVAÇÃO DO SOLO E DA ÁGUA, 14., 2002, Cuiabá. Anais... 